\title{
Systems pharmacology assessment of the 5-fluorouracil pathway
}

\author{
Filipe A Muhale ${ }^{1,2}$, Barbara A Wetmore ${ }^{2}$, Russell S Thomas ${ }^{1,2}$, and Howard L McLeod ${ }^{\dagger, 1}$ \\ ${ }^{1}$ UNC Institute for Pharmacogenomics \& Individualized Therapy, Lineberger Comprehensive \\ Cancer Center, University of North Carolina, Chapel Hill, NC 27599-7361, USA
}

${ }^{2}$ The Hamner Institutes for Health Sciences, Research Triangle Park, NC 27361, USA

\section{Abstract}

\begin{abstract}
Aim-To assess the impact of the 5-fluorouracil (5-FU) drug-pathway genes on cytotoxicity, and determine whether loss-of-function analyses coupled with functional assays can help prioritize pharmacogenomic candidate genes.
\end{abstract}

Materials \& methods-Dose-response experiments were used to quantify the phenotype of sensitivity to 5-FU following the specific knockdown of genes selected from the 5-FU PharmGKB drug pathway in three human colorectal cell lines. Changes in sensitivity were considered significant if the $\mathrm{IC}_{50}$ for shRNA-exposed cells were three standard deviations outside the mean $\mathrm{IC}_{50}$ for control-treated cells.

Results-Of the 24 genes analyzed, 13 produced significant changes on the phenotype of sensitivity to 5-FU (DHFR, DPYS, DTYMK, DUT, FPGS, GGH, NME1, NT5C, RRM1, TYMS, $U C K 2, U N G$ and $U M P S$ ).

Conclusion-The RNAi screening strategy enabled prioritization of the genes from the 5-FU drug pathway. Further validation of the genes credentialed in this study should include gene activity or expression and mutation analyses of clinical samples.

\section{Keywords}

5-fluorouracil pathway; candidate genes prioritization; colon cancer; pharmacogenomics; RNAi

\begin{abstract}
5-fluorouracil (5-FU) is widely used in the therapy of solid tumors, including colorectal, breast, head and neck cancers. The clinical efficacy of 5-FU can be improved significantly by associating 5-FU with biochemical modulators such as folinic acid (leucovorin), used in combination with synergic drugs such as oxaliplatin and irinotecan [1,2], or by the addition of monoclonal antibodies directed against VEGF or EGF receptor [3-5]. Toxicity remains a major limitation in the clinical efficacy of 5-FU. Although 5-FU was developed approximately 50 years ago, based on the concept that it would kill cancer cells by acting as
\end{abstract}

\footnotetext{
() 2011 Future Medicine Ltd

${ }^{\dagger}$ Author for correspondence: Tel.: +1 919966 0512, Fax: +1 919966 5863, hmcleod@unc.edu.

Financial \& competing interests discolure The authors have no other relevant affiliations or financial involvement with any organization or entity with a financial interest in or financial conflict with the subject matter or materials discussed in the manuscript apart from those disclosed.

No writing assistance was utilized in the production of this manuscript.

Ethical conduct of research

The authors state that they have obtained appropriate institutional review board approval or have followed the principles outlined in the Declaration of Helsinki for all human or animal experimental investigations. In addition, for investigations involving human subjects, informed consent has been obtained from the participants involved.
} 
a competitive antagonist of uracil, many aspects of its mechanism of action remain to been fully characterized [6]. 5-FU is regulated via a complex network of anabolic and catabolic genes (Figure 1). 5-FU is inactivated by catabolism into fluorinated $\beta$-alanine [7] via the sequential activities of gene products from dihydropyrimidine dehydrogenase (DPYD), dihydropyrimidinase (DPYS) and ureidopropionase $\beta$ (UPB1). Patients with congenital deficiency in DPYD can experience 5-FU side effects, including severe myelo-suppression, cardiac toxicity, mucositis and hand-foot syndrome owing to prolonged exposure to the drug [8]. The prevalence of DPYD partial deficiency in the general population is approximately 5\% and total deficiency is rare at approximately $0.2 \%$ [9-11]. Partial or complete DPYD deficiency is linked to genetic modifications, including SNPs, [11], deletion mutations [12,13] and methylation [14]. 5-FU catabolism can also be impaired by genetic alterations in DPYS [15,16] or UPB1 [17-19].

Early biochemical studies demonstrated that 5 -FU could be metabolized through complex anabolic pathways into several active metabolites that kill cells by disrupting DNA or RNA synthesis or by inhibiting the enzymes required in pyrimidine synthesis (Figure 1) [20]. The 5-FU metabolite 5-fluoro-2'-deoxyuridine (FdUMP) inhibits the activity of thymidylate synthase (TYMS) by forming a covalent ternary complex involving FdUMP, TYMS and 5,10-methylenetetrahydrofolate. Since cells rely on thymidylate synthase activity for $d e$ novo DNA synthesis and repair, thymidylate synthase inhibition by FdUMP is believed to be the main mechanism by which 5-FU exerts its cytotoxic, and by extension, therapeutic effects [1]. FdUMP is formed as a result of the activities of the gene products of thymidine phosphorylase (TYMP or ECGF1) and thymidine kinase 1. 5-FU can also be converted into 5-fluorouridine monophosphate (FUMP) via a direct mechanism involving orotate phosphoribosyl transferase (OPRT; gene product of uridine monophosphate synthase [UMPS]) or indirectly by the actions of uridine phosphorylase 1 and uridine kinase (UCK2). FUMP is the precursor for the formation of two other cytotoxic metabolites: deoxyuridine triphosphate (dUTP) and 5-fluorouridine triphosphate. The metabolite dUTP is cytotoxic after its misincorporation into DNA where it causes irreparable DNA damage during synthesis and repair. 5-fluorouridine triphosphate misincorporation into different RNA structures kill cells by disrupting their cellular metabolism and homeostasis [21,22].

Most studies of 5-FU resistance have focused on TYMS. Overexpression of TYMS mRNA and its protein is linked to resistance to 5-FU, both in vitro and in vivo [23,24]. Genetic alterations leading to modifications in TYMS include polymorphisms in the TYMS promoter region [25] and copy number variation [26]. In addition to TYMS expression, increased expression in tumor cells of other enzymes from the 5-FU metabolic pathway such as DPYD [27,28], or thymidine phosphorylase [29] have been correlated with resistance to 5-FU. Studies investigating the role of tumor suppressor p53 in modulating the response to 5-FU is contradictory at best. While in vitro studies demonstrated that loss of p53 confers cell resistance to 5-FU [30], another study demonstrated that increased p53 expression in tumor tissue correlated with 5-FU resistance [31]. Yet another study suggested that p53 had no predictive value in the outcome of 5-FU-based therapy [32].

Given the many potential regulators of 5-FU activity, we performed a large-scale credentialing study of 5-FU pathway genes across multiple human colorectal cancer cell lines to provide quantitative data on key candidates for individualized therapy studies.

\section{Materials \& methods}

\section{Cell lines}

Colorectal cell lines HCT-116, SW620 and HT-29 were acquired from American Type Culture Collection (ATCC, VA, USA). HCT-116 cells were cultured in McCoy's 5A 
medium (Cellgro, VA, USA) containing $0.075 \%$ sodium bicarbonate (Cellgro). SW620 and HT-29 cells were cultured in RPMI 1640 and DMEM, respectively (both purchased from Gibco, CA, USA). All cell culture media were supplemented with $10 \%$ fetal bovine serum (Sigma, MO, USA) and $100 \mathrm{U} / \mathrm{ml}$ penicillin and streptomycin (Cellgro). Cell cultures were incubated at $37^{\circ} \mathrm{C}$ and $5 \% \mathrm{CO}_{2}$ in a humidified atmosphere.

\section{Plasmid shRNA}

The OpenBiosystems (AL, USA) plasmid shRNA bacterial glycerol stocks were obtained through the University of North Carolina at Chapel Hill (NC, USA) Lenti-shRNA Core. To ensure that changes in phenotype were mediated by RNAi and not owing to off-target effects, each gene in the library was represented by four-five distinct shRNA plasmids. For hit selection, the phenotype had to be produced by at least two plasmids [33,34]. A plasmid expressing the shRNA directed against the gene enhanced Green Fluorescence Protein (eGFP; a nonmammalian gene) was used as a negative control. The plasmids were isolated using the Macherey-Nagel (PA, USA) NucleoSpin Robot-96 plasmid kit. Briefly, bacteria were inoculated in Terrific Broth medium (MP Biomedicals, OH, USA) containing $100 \mu \mathrm{g} /$ $\mathrm{ml}$ of Carbenicillin (Invitrogen, CA, USA) utilizing 96-well MN Square-well Blocks, grown in a GeneMachines HiGro rotative incubator (CA, USA).

\section{Transfection procedure}

Exponentially growing colorectal cell lines (passages 5-15) were seeded at a density of 20,000 cells per well in 96-well plates and incubated overnight as described above. The following day, media was aspirated and replaced with $50 \mu \mathrm{l}$ of warm fresh complete media. Cells were transfected with plasmid-liposome complexes composed of $100 \mathrm{ng}$ plasmid shRNA and $0.5 \mu \mathrm{g}$ Lipofectamine 2000 (Invitrogen) in a final volume of $50 \mu \mathrm{l} \mathrm{Opti- \textrm {MEM } ^ { \circledR }}$ I (Invitrogen). A total of $18 \mathrm{~h}$ following transfection, media was aspirated and cells were dissociated by incubation with $0.05 \%$ trypsin- $53 \mathrm{mM}$ EDTA in Hank's Balanced Salt Solution (HBSS; Cellgro). Transfectants were seeded in 384-well plates at a density of 1000 cells/well (32 wells/transfectant) and incubated for an additional $24 \mathrm{~h}$. Liquid dispensing to the 384-well plates was performed using a Tecan Freedom EVO ${ }^{\circledR}$ liquid dispenser (Tecan, Männedorf, Switzerland).

\section{Verification of RNAi effects on the phenotypes of sensitivity to 5-FU}

To determine if the modifications observed in the phenotypes of sensitivity to 5-FU resulted from the combined effects of specific gene knockdown in each one of the three colorectal cell lines and 5-FU, we determined mRNA levels for the selected genes by quantitative realtime PCR (qPCR). Individual transfections with two-three of the most effective shRNAs/ genes were performed as described above. A total of $48 \mathrm{~h}$ following transfection, total RNA was isolated using the Trizol method (Invitrogen). A total of $300 \mathrm{ng}$ of total RNA was reverse transcribed with the Moloney murine leukemia virus reverse transcriptase (MMLUV; NE Biolabs, MA, USA) according to manufacturer's instructions. Prevalidated primers for qPCR were purchased from RealTimePrimers.com (Elkins Park, PA, USA, Supplementary Table 1; see www.futuremedicine.com/doi/supp1/10.2217/pgs.10.188) [101]. Real-time PCR reactions were carried out in 384 well MicroAmp ${ }^{\circledR}$ Optical 384-Well Reaction Plates (Applied Biosystems [ABI], CA, USA) and run as triplicates on a 7900HT thermocycler (ABI). The reaction conditions were $95^{\circ} \mathrm{C}$ for $10 \mathrm{~min}$, followed by 40 cycles at $95^{\circ} \mathrm{C}(15 \mathrm{~s})$ and $58^{\circ} \mathrm{C}(1 \mathrm{~min})$ in $15 \mu \mathrm{l}$ reaction mixture composed of $7.5 \mu \mathrm{l}$ of $\mathrm{SYBR}^{\circledR}$ Green PCR Master Mix (ABI), $0.1 \mu \mathrm{M}$ of both primers and $15 \mathrm{ng}$ of cDNA. For the analysis of qPCR data, the cycle thresholds (Ct) were normalized with RPLP0 [35] and baseline expression levels were the normalized Cts from eGFP-shRNA transfectants. Relative expression levels of target mRNA following shRNA transfection were calculated as percentage of remaining mRNA levels with the expression ' $\Delta \Delta \mathrm{Ct} \times 100$ ' [36]. 


\section{Cytotoxicity assay}

Transfectants from each shRNA were treated with vehicle (media) or 5-FU over seven log concentrations from $0.001-1000 \mu \mathrm{M}$ (four replicates at each dose). A total of $96 \mathrm{~h} \mathrm{later,}$ AlamarBlue (Invitrogen) was added (10\% final concentration); 6-8 h later fluorescence values were acquired using the Tecan 1000 Multiplate Reader (Tecan). The fluorescence readings were corrected for the blank before being converted into percentage cell survival at each drug concentration and $\mathrm{IC}_{50}$ was determined from the dose-response curves utilizing XLfit4.0 software from IDBS (IDBS, Guildford, UK). Figure 2 is an example of representative phenotypes in the screen. The $Z$ '-factors were greater than 0.7 , therefore this system was considered suitable for analyzing the impact of gene knockdown in cell sensitivity to 5-FU [37].

\section{Statistical methods}

A plasmid shRNA was considered as 'active' when the resulting $\mathrm{IC}_{50}$ was shifted at least three standard deviations from that found with the control shRNA-plasmid eGFP. In a given cell line, a gene with two or more plasmids producing the same phenotype was considered 'active'. A gene was selected as 'credentialed' in the 5-FU pathway when its knockdown significantly altered $\mathrm{IC}_{50}$ in the HCT-116 cells (p53 wild-type) and at least one of the two cell lines with mutated p53 (SW620 or HT-29 cells) and demonstrated a mean percentage of remaining $\mathrm{mRNA} \pm$ standard deviation of $40 \%$ or less as determined by qPCR.

\section{Results}

Loss of function analyses identify $\mathbf{1 3}$ genes involved in the modulation of 5-FU cytotoxicity

Of the 24 5-FU PharmGKB [102] drug pathway genes analyzed, knockdown of 13 of them produced a significant change in cytotoxicity (Figures $2 \& 3$ ). A total of 12 of these genes increased sensitivity to 5-FU cytotoxicity 3-12-fold, and only one gene, UMPS, increased resistance by approximately twofold (Figure 4).

\section{Confirmation of gene knockdown by qPCR}

A total of $48 \mathrm{~h}$ after transfection with shRNA plasmids, mRNA levels for the selected genes were measured by qPCR to confirm gene knockdown. For all three cell lines, mRNA levels were consistently diminished to $10-40 \%$ of control levels (Figure 5), indicating that the observed phenotypes were associated with specific gene knockdown.

\section{Conversion of 5-FU into FUMP plays a major role in the cytotoxic effects of 5-FU}

The knockdown of UMPS gene resulted in a significant shift in the $\mathrm{IC}_{50}$ (Figures $2 \& 3$ ), and a approximately twofold increase in cell resistance to 5-FU in both HCT-116 and SW620 cell lines (Figure 4), demonstrating that UMPS, the gene responsible for the conversion of 5FU into FUMP, is a relevant gene in the 5-FU pathway. The knockdown of UCK2 and $N T 5 C$, genes also involved in FUMP synthesis from 5-FU, resulted in a significant decrease of the $\mathrm{IC}_{50}$ of a magnitude of 3- to 6-fold in all three cell lines. NME1, UNG and RRM1 produced a significant shift in the $\mathrm{IC}_{50}$ (a decrease of 4- to 13-fold) in all three cell lines (Figures $3 \& 4$ ), indicating that $N M E 1, U N G$ and $R R M 1$ may be mediators of 5-FU drug pathway.

\section{Knockdown of genes involved in thymidine biosynthesis sensitizes cells to 5-FU}

The knockdown of the TYMS gene resulted in a 3-8-fold enhancement of the cytotoxic effects of 5-FU in all three cell lines. Two additional genes involved in thymidine synthesis also produced a significant decrease in $\mathrm{IC}_{50}$ following knockdown: DTYMK (threefold 
decrease in HT-29 cell lines and approximately fivefold decrease in HCT-116 cells) and DUT with 13- and three-fold reduction, respectively, in HCT-116 and SW620 cells.

\section{Disturbance of folate homeostasis increases the cytotoxic effects of 5-FU}

Knockdown of two genes involved in the homeostasis of folates, namely DHFR and GGH, produced a significant decrease of the $\mathrm{IC}_{50}$ in all three cell lines (3-10-fold), whereas reduced activity of $F P G S$ resulted in a significant decrease in the $\mathrm{IC}_{50}$ by three- and six-fold in HCT-116 and HT-29 cell lines, respectively (Figure 4).

\section{Apoptosis-related genes from the 5-FU pathway do not influence sensitivity}

5 -fluorouracil is known to induce apoptosis in human cancer cells. However, the candidate apoptosis genes from the 5-FU PharmGKB pathway (FDXR, TP53, FASLG and NFKB1) did not demonstrate a significant change in sensitivity to 5-FU following specific knockdown (Figure 3), suggesting that other genes might modulate cell death by apoptosis induced by 5FU in these cell lines.

\section{Modulation of 5-FU catabolic pathway by DPYD}

The DPYD gene knockdown did not significantly modify the phenotype of sensitivity to 5FU in HCT-116 and HT-29 cell lines (Figure 3), whereas the depletion of DPYS geneactivity resulted in a significant reinforcement of 5-FU-induced cytotoxicity in all three cells lines (fold change of the $\mathrm{IC}_{50}$ ranged from approximately 3-7, Figure 4). UPB1 gene knockdown produced a significant increase in the $\mathrm{IC}_{50}$ in the SW620 and HT-29 cell lines (both with mutated p53), but not in the HCT-116 cells (with wild-type p53, Figure 3). Therefore, amongst the three genes of the 5-FU catabolic pathway, in this platform, only $D P Y S$ was credentialed as a modulator of the 5-FU pathway.

\section{Discussion}

Variability in patient response to drug therapy is a major hurdle in the delivery of optimal efficacy in anticancer chemotherapy. The PharmGKB drug pathway effort is an important tool for conceptualizing sources of variability of therapy outcome. The ability to identify those genes within a drug pathway most likely to modulate therapeutic outcome is paramount in establishing individualized therapy.

We exploited the flexibility of a platform of RNAi reagents and a cell panel of three colorectal cell lines to determine the roles of 24 genes from the PharmGKB pathway in the phenotype of sensitivity to 5-FU. We were able to identify 13 genes as modulators of the 5FU drug pathway (Figure 6A). The mRNA levels of the genes we analyzed were reduced by more than $60 \%$, as determined by qPCR. Thus, the RNAi screening strategy we used is a useful tool for prioritization of the genes from the 5-FU drug pathway. Interestingly, seven of the genes we validated (DHFR, FPGS, GGH, NME1, UCK2, UMPS and UNG) were previously found to be differentially expressed between tumor samples and its adjacent normal tissue in 52 patients with Dukes C colorectal cancer [38]. Therefore, the in vitro system we developed may be useful in predicting experimentally, which pharmacogenomic genes are most likely to be cancer drug biomarkers.

The gene product of UMPS is the enzyme OPRT, which converts 5-FU into FUMP, a common substrate for the production of 5-fluorouridine triphosphate and dUTP, two cytotoxic metabolites that target RNA and DNA, respectively. Our data demonstrated that in the 5-FU anabolic pathway UMPS was the only gene that produces a cellular phenotype of 5-FU resistance, suggesting that in this cellular system, the misincorporation of 5-FU metabolites into RNA and DNA are important in the initiation of 5-FU cytotoxicity (Figure 
6B). Furthermore, there is some evidence to suggest that an increase of UMPS mRNA expression is observed in tumor tissue when compared with adjacent normal tissue $[7,38,39]$. In addition, high OPRT activity or increased UMPS mRNA expression are associated with greater survival $[39,40]$, suggesting that UMPS may play roles of clinical relevance in 5-FU-based chemotherapy regimens.

Although TYMS is considered an important molecular target of 5-FU [1,41], our results demonstrated that ten additional genes of the 5-FU anabolic pathway (DHFR, DTYMK, DUT, FPGS, GGH, NME1, NT5C, RRM1, UCK2 and $U N G$ ), produced a phenotype of cell sensitization to 5-FU following knockdown. The disruption of the activity of TYMS or DHFR, GGH, DUT, DTYMK and FPGS interferes with thymidine synthesis (Figure 6B), whereas the knockdown of NME1, RRM1, UCK2 and $U N G$, all genes acting downstream of UMPS, affect cell viability by interfering with RNA or DNA synthesis (Figure 6B). Thus, the cytotoxic effects of 5-FU might be under the regulation of complex mechanisms, implicating not only TYMS, but at least these ten other genes credentialated in this study.

The knockdown of DPYS produced a robust phenotype of sensitization in all three cell lines, indicating that changes in DPYS gene-activity may be influential in 5-FU clearance. Since congenital DPYS deficiencies do not always cause clinical abnormities [15], our results suggest that DPYS should be considered for future studies aimed at understanding the mechanisms of 5-FU toxicity. The knockdown of DPYD, a gene with a well established role in fluoropyrimydine toxicity [8], did not result in significant changes in cell sensitivity, which may reflect a limitation in our screening panel in capturing all modulators. Mutations in UPBI can affect patients' response to 5-FU therapy [17], and our results suggest that UPB1 may influence 5-FU catabolism when p53 is mutated. Taken as a whole, our observations indicate that DPYS and UPB1 should also be considered more carefully in the study of 5-FU toxicity.

We have developed an in vitro platform for the credentialing of pharmacogenomic candidate genes identified from known drug pathways. This system can also be applied in the analyses of genes from chromosomal regions identified through whole-genome studies or other discovery approaches [42]. This approach can be expanded to different cell types, larger number of cell lines per tumor type, or other ways that maximize its utility in future pharmacogenomic studies. The data generated by this approach can be used to create dynamic drug pathways that reflect the relative impact of a gene on a given drug therapy. This information will then be useful to prioritize gene-variant discovery and focus studies on modulating chemotherapeutic response. Studies on the genes prevalidated in vitro could then be further investigated in order to determine the genetic modifications with the potential to impact in the clinic, for example, via SNP analyses (Supplementary Table 2; see www.future-medicine.com/doi/suppl/10.2217/pgs.10.188) or gene copy number variation. The findings from these studies should impact tremendously on the reduction of the scope of genes to be considered in future pharmacogenomic clinical trials.

\section{Supplementary Material}

Refer to Web version on PubMed Central for supplementary material.

\section{Acknowledgments}

This study was supported by the NIH Pharmacogenetic Research Network (U01GM63341) and NCI GI SPORE NCI (Gastrointestinal Specialized Programs of Research Excellence grant P50 CA106991). Dr McLeod serves as a consultant to Myriad Genetics and Medco Health Solutions. 


\section{Bibliography}

1. Santi DV, McHenry CS. 5-fluoro-2-deoxyuridylate: covalent complex with thymidylate synthetase. Proc Natl Acad Sci USA. 1972; 69(7):1855-1857. [PubMed: 4505665]

2. de Gramont A, Figer A, Seymour M, et al. Leucovorin and fluorouracil with or without oxaliplatin as first-line treatment in advanced colorectal cancer. J Clin Oncol. 2000; 18(16):2938-2947. [PubMed: 10944126]

3. Tol J, Koopman M, Cats A, et al. Chemotherapy, bevacizumab, and cetuximab in metastatic colorectal cancer. N Engl J Med. 2009; 360(6):563-572. [PubMed: 19196673]

4. Cassidy J, Saltz L, Giantonio B, Kabbinavar F, Hurwitz H, Rohr UP. Effect of bevacizumab in older patients with metastatic colorectal cancer: pooled analysis of four randomized studies. J Cancer Res Clin Oncol. 2010; 136(5):737-743. [PubMed: 19904559]

5. Hurwitz HI, Fehrenbacher L, Hainsworth JD, et al. Bevacizumab in combination with fluorouracil and leucovorin: an active regimen for first-line metastatic colorectal cancer. J Clin Oncol. 2005; 23(15):3502-3508. [PubMed: 15908660]

6. Diasio RB, Harris BE. Clinical parmacology of 5-fuorouracil. Clin Pharmacokinet. 1989; 16(4): 215-237. [PubMed: 2656050]

7. Heggie GD, Sommadossi JP, Cross DS, Huster WJ, Diasio RB. Clinical pharmacokinetics of 5fluorouracil and its metabolites in plasma, urine, and bile. Cancer Res. 1987; 47(8):2203-2206. [PubMed: 3829006]

8. Yen JL, McLeod HL. Should DPD analysis be required prior to prescribing fluoropyrimidines? Eur J Cancer. 2007; 43(6):1011-1016. [PubMed: 17350823]

9. Etienne M, Lagrange J, Dassonville O, et al. Population study of dihydropyrimidine dehydrogenase in cancer patients. J Clin Oncol. 1994; 12(11):2248-2253. [PubMed: 7964939]

10. Lu Z, Zhang R, Carpenter JT, Diasio RB. Decreased dihydropyrimidine dehydrogenase activity in a population of patients with breast cancer: implication for 5-fluorouracil-based chemotherapy. Clin Cancer Res. 1998; 4(2):325-329. [PubMed: 9516918]

11. Ridge SA, Sludden J, Brown O, et al. Dihydropyrimidine dehydrogenase pharmacogenetics in Caucasian subjects. Br J Clin Pharmacol. 1998; 46(2):151-156. [PubMed: 9723824]

12. Öfverholm A, Arkblad E, Skrtic S, Albertsson P, Shubbar E, Enerbäck C. Two cases of 5fluorouracil toxicity linked with gene variants in the DPYD gene. Clin Biochem. 2010; 43(3):331334. [PubMed: 19822137]

13. Johnson MR, Wang K, Tillmanns S, Albin N, Diasio RB. Structural organization of the human dihydropyrimidine dehydrogenase gene. Cancer Res. 1997; 57(9):1660-1663. [PubMed: 9135003]

14. Yu J, McLeod HL. Methylation of the DPYD promoter and dihydropyrimidine dehydrogenase deficiency. Clin Cancer Res. 2006; 12(12):3864-3864. [PubMed: 16778115]

15. Sumi S, Imaeda M, Kidouchi K, et al. Population and family studies of dihydropyrimidinuria: prevalence, inheritance mode, and risk of fluorouracil toxicity. Am J Med Genet. 1998; 78(4):336340. [PubMed: 9714435]

16. van Kuilenburg AB, Meinsma R, Zonnenberg BA, et al. Dihydropyrimidinase deficiency and severe 5-fluorouracil toxicity. Clin Cancer Res. 2003; 9(12):4363-4367. [PubMed: 14555507]

17. Thomas HR, Ezzeldin HH, Guarcello V, Mattison LK, Fridley BL, Diasio RB. Genetic regulation of $\beta$-ureidopropionase and its possible implication in altered uracil catabolism. Pharmacogenet Genomics. 2008; 18(1):25-35. [PubMed: 18216719]

18. van Kuilenburg AB, Meinsma R, Beke E, et al. $\beta$-ureidopropionase deficiency: an inborn error of pyrimidine degradation associated with neurological abnormalities. Hum Mol Genet. 2004; 13(22):2793-2801. [PubMed: 15385443]

19. Yaplito-Lee J, Pitt J, Meijer J, Zoetekouw L, Meinsma R, van Kuilenburg AB. $\beta$-ureidopropionase deficiency presenting with congenital anomalies of the urogenital and colorectal systems. Mol Genet Metab. 2008; 93(2):190-194. [PubMed: 17964839]

20. Pinedo H, Peters G. Fluorouracil: biochemistry and pharmacology. J Clin Oncol. 1988; 6(10): 1653-1664. [PubMed: 3049954] 
21. Ghoshal K, Jacob ST. Specific inhibition of pre-ribosomal RNA processing in extracts from the lymphosarcoma cells treated with 5-fluorouracil. Cancer Res. 1994; 54(3):632-636. [PubMed: 8306322]

22. Zhao X, Yu YT. Incorporation of 5-fluorouracil into U2 snRNA blocks pseudouridylation and premRNA splicing in vivo. Nucl Acids Res. 2007; 35(2):550-558. [PubMed: 17169984]

23. Johnston PG, Lenz HJ, Leichman CG, et al. Thymidylate synthase gene and protein expression correlate and are associated with response to 5-fluorouracil in human colorectal and gastric tumors. Cancer Res. 1995; 55(7):1407-1412. [PubMed: 7882343]

24. Leichman C, Lenz H, Leichman L, et al. Quantitation of intratumoral thymidylate synthase expression predicts for disseminated colorectal cancer response and resistance to protractedinfusion fluorouracil and weekly leucovorin. J Clin Oncol. 1997; 15(10):3223-3229. [PubMed: 9336359]

25. Marsh S. Thymidylate synthase pharmacogenetics. Invest New Drugs. 2005; 23(6):533-537. [PubMed: 16267625]

26. Wang TL, Diaz LA, Romans K, et al. Digital karyotyping identifies thymidylate synthase amplification as a mechanism of resistance to 5-fluorouracil in metastatic colorectal cancer patients. Proc Natl Acad Sci USA. 2004; 101(9):3089-3094. [PubMed: 14970324]

27. Oguri T, Achiwa H, Bessho Y, et al. The role of thymidylate synthase and dihydropyrimidine dehydrogenase in resistance to 5-fluorouracil in human lung cancer cells. Lung Cancer. 2005; 49(3):345-351. [PubMed: 15993511]

28. Jensen SA, Vainer B, Sørensen JB. The prognostic significance of thymidylate synthase and dihydropyrimidine dehydrogenase in colorectal cancer of 303 patients adjuvantly treated with 5fluorouracil. Int J Cancer. 2007; 120(3):694-701. [PubMed: 17096352]

29. Soong R, Shah N, Salto-Tellez M, et al. Prognostic significance of thymidylate synthase, dihydropyrimidine dehydrogenase and thymidine phosphorylase protein expression in colorectal cancer patients treated with or without 5-fluorouracil-based chemotherapy. Ann Oncol. 2008; 19(5):915-919. [PubMed: 18245778]

30. Bunz F, Hwang PM, Torrance C, et al. Disruption of p53 in human cancer cells alters the responses to therapeutic agents. J Clin Invest. 1999; 104(3):263-269. [PubMed: 10430607]

31. Liang JT, Huang KC, Cheng YM, et al. P53 overexpression predicts poor chemosensitivity to highdose 5-fluorouracil plus leucovorin chemotherapy for stage IV colorectal cancers after palliative bowel resection. Int J Cancer. 2002; 97(4):451-457. [PubMed: 11802206]

32. Jakob C, Liersch T, Meyer WP, et al. Immunohistochemical analysis of thymidylate synthase, thymidine phosphorylase, and dihydropyrimidine dehydrogenase in rectal cancer (cUICC II/III): correlation with histopathologic tumor regression after 5-fluorouracil-based long-term neoadjuvant chemoradiotherapy. Am J Surg Pathol. 2005; 29(10):1304-1309. [PubMed: 16160472]

33. Moffat J, Grueneberg DA, Yang X, et al. A lentiviral RNAi library for human and mouse genes applied to an arrayed viral high-content screen. Cell. 2006; 124(6):1283-1298. [PubMed: 16564017]

34. Jackson AL, Linsley PS. Recognizing and avoiding siRNA off-target effects for target identification and therapeutic application. Nat Rev Drug Discov. 2010; 9(1):57-67. [PubMed: 20043028]

35. Dydensborg AB, Herring E, Auclair J, Tremblay E, Beaulieu JF. Normalizing genes for quantitative RT-PCR in differentiating human intestinal epithelial cells and adenocarcinomas of the colon. Am J Physiol Gastrointest Liver Physiol. 2006; 290(5):G1067-G1074. [PubMed: 16399877]

36. Cheng A, Johnson CL, Ford LP. A step-by-step procedure to analyze the efficacy of siRNA using real-time PCR. Methods Mol Biol. 2008; 419:303-316. [PubMed: 18369992]

37. Zhang JH, Chung TD, Oldenburg KR. A simple statistical parameter for use in evaluation and validation of high throughput screening assays. J Biomol Screen. 1999; 4(2):67-73. [PubMed: 10838414]

38. Kidd EA, Yu J, Li X, Shannon WD, Watson MA, McLeod HL. Variance in the expression of 5fluorouracil pathway genes in colorectal cancer. Clin Cancer Res. 2005; 11(7):2612-2619.

[PubMed: 15814641] 
39. Koizumi W, Tanabe S, Azuma M, et al. Impacts of fluorouracil-metabolizing enzymes on the outcomes of patients treated with S-1 alone or S-1 plus cisplatin for first-line treatment of advanced gastric cancer. Int J Cancer. 2010; 126(1):162-170. [PubMed: 19588501]

40. Ishikawa M, Miyauchi T, Kashiwagi Y. Clinical implications of thymidylate synthetase, dihydropyrimidine dehydrogenase and orotate phosphoribosyl transferase activity levels in colorectal carcinoma following radical resection and administration of adjuvant 5-FU chemotherapy. BMC Cancer. 2008; 8(1):188. [PubMed: 18597678]

41. Carreras CW, Santi DV. The catalytic mechanism and structure of thymidylate synthase. Ann Rev Biochem. 1995; 64(1):721-762. [PubMed: 7574499]

42. Watters JW, Kraja A, Meucci MA, Province MA, McLeod HL. Genome-wide discovery of loci influencing chemotherapy cytotoxicity. Proc Natl Acad Sci USA. 2004; 101(32):11809-11814. [PubMed: 15282376]

\section{Websites}

101. Real Time Primers. http:I\RealTimePrimers.com

102. PharmGKB. www.pharmgkb.org 
Executive summary

- The phenotype of sensitivity to drugs may be modulated by some of the genes from the 5-fluorouracil (5-FU) drug pathway.

- $\quad$ RNAi strategy was used to prioritize genes from the 5-FU pathway.

- Our findings suggests that $U M P S$ can be one of the major regulators of the cytotoxic effects of 5-FU.

- $\quad$ In addition to TYMS this study demonstrate that other genes from the 5-FU metabolic pathway (DHFR, DTYMK, DUT, FPGS, GGH, NME1, NT5C, $R R M 1, U C K 2$ and $U N G)$ may be involved in the cytotoxic effects of 5-FU.

- This RNAi screening platform can capture most, but not all of the drugpathway gene regulators. 


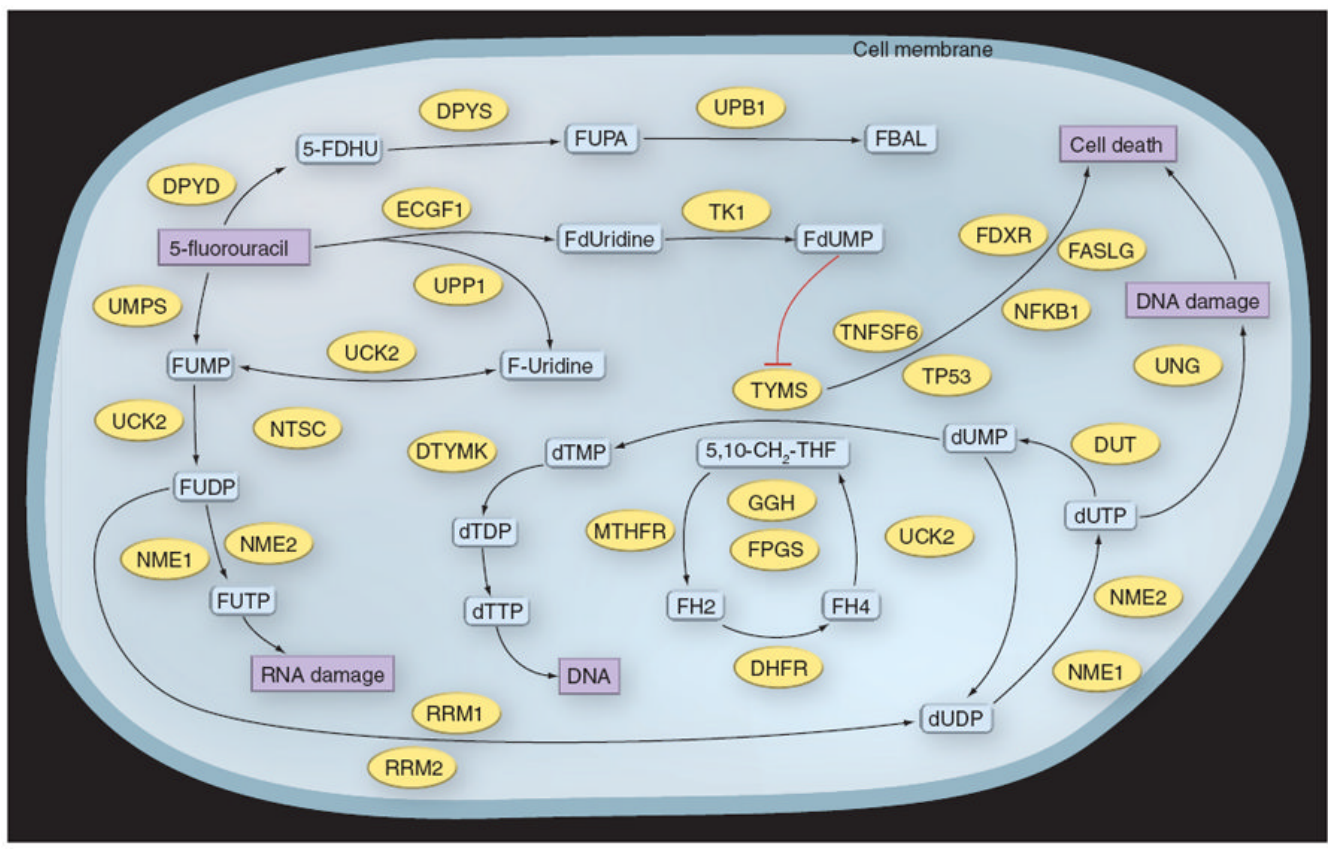

Figure 1. PharmGKB 5-fluorouracil drug pathway

Enzyme names are shown in yellow oval circles, and their interacting metabolites are represented in blue octagonal circles.

Adapted with permission from [102]. 


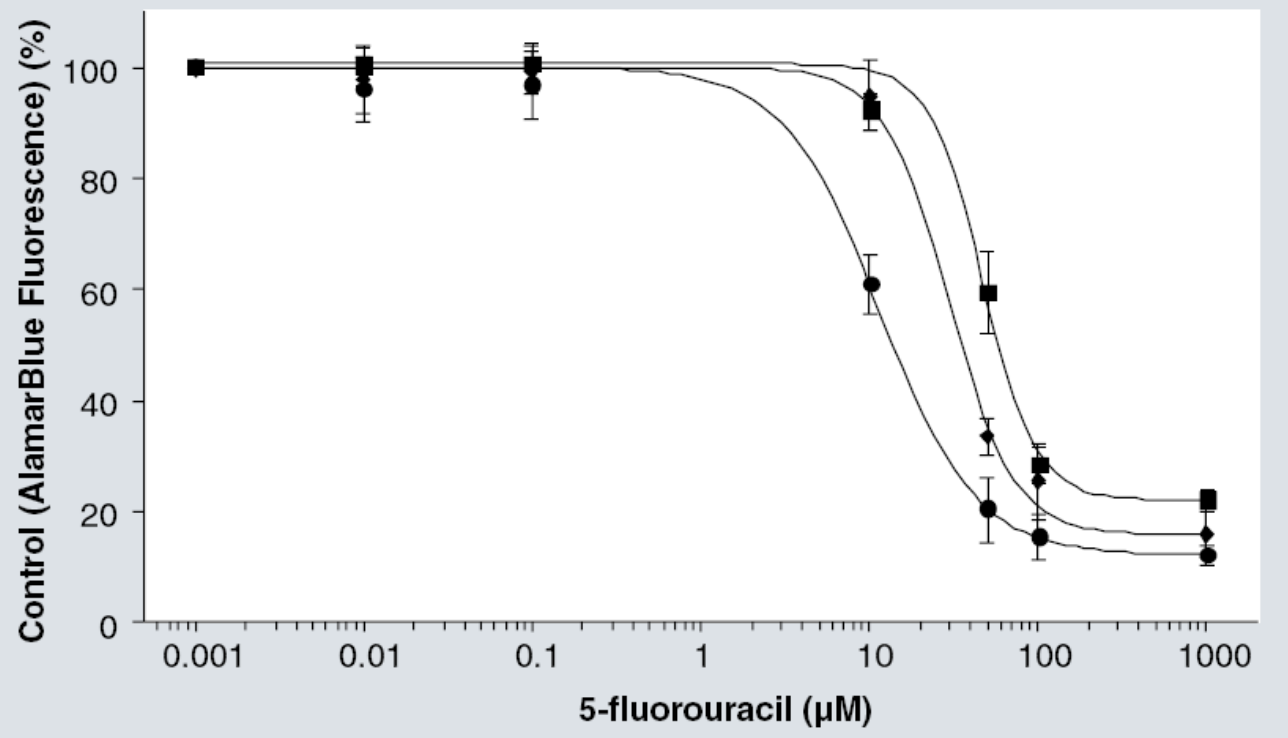

Figure 2. Dose-response plots for 5-fluorouracil; in HCT-116 cells transfected with control shRNA Green Fluorescence Protein (diamonds), uridine monophosphate synthase shRNA (squares) and dihydropyrimidine dehydrogenase shRNA (circles)

Each data point is the mean percentage survival \pm standard deviation for four replicates at each drug concentration. 


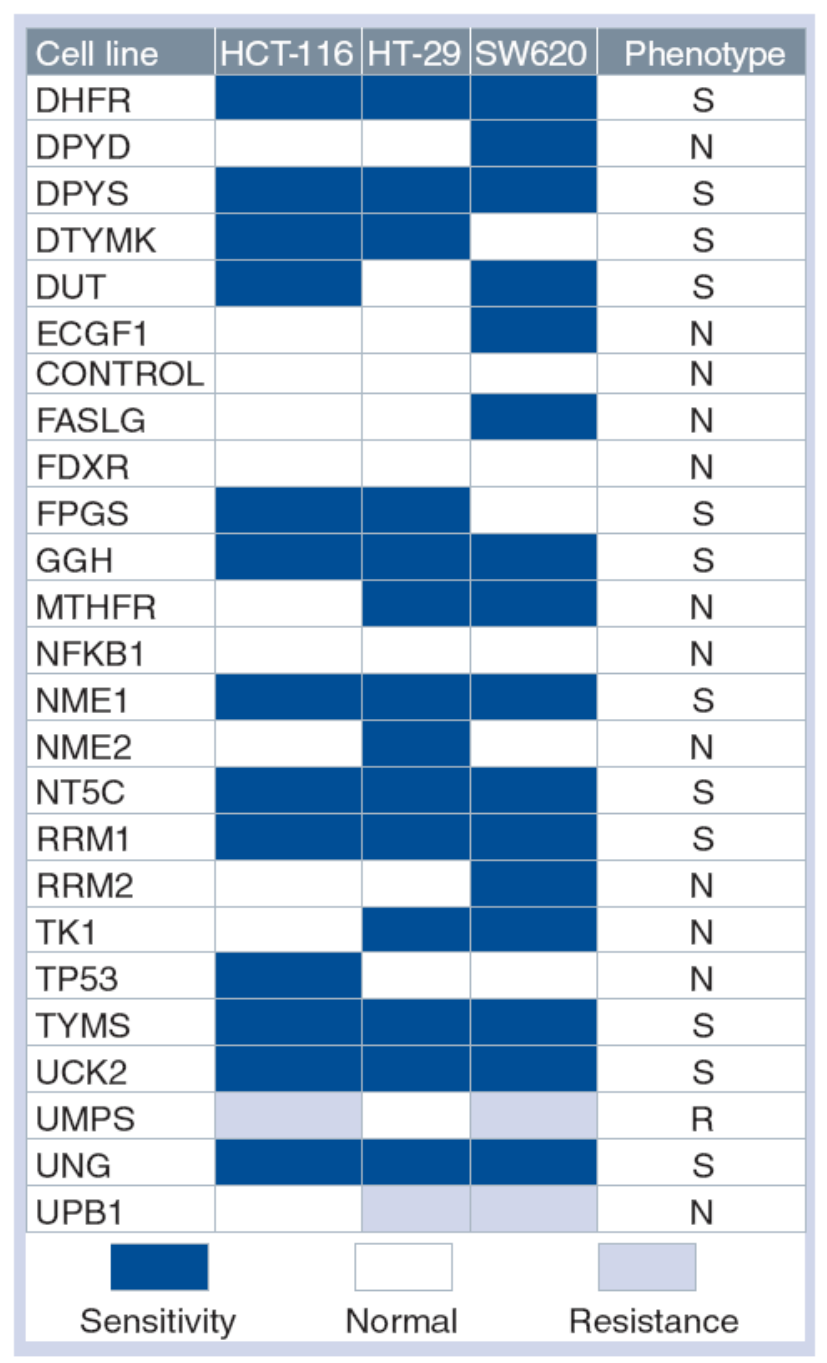

Figure 3. Phenotypes of sensitivity of the genes from the 5-fluorouracil pathway following gene knockdown in colorectal cell lines

Profiles of sensitivity to 5-fluorouracil in each cell line were determined according to mean $\mathrm{IC}_{50}$ values for 2-3 shRNAs producing the same phenotype. Phenotype of sensitivity (dark blue boxes; mean $\mathrm{IC}_{50} \leq$ mean $\mathrm{IC}_{50}$ control -3 standard deviation [SD]), resistance (light blue boxes; mean $\mathrm{IC}_{50} \geq$ mean $\mathrm{IC}_{50}$ control +3 SD normal sensitivity (white boxes; mean $\mathrm{IC}_{50}$ within the range mean $\mathrm{IC}_{50}$ control $\pm 3 \mathrm{SD}$ ). 

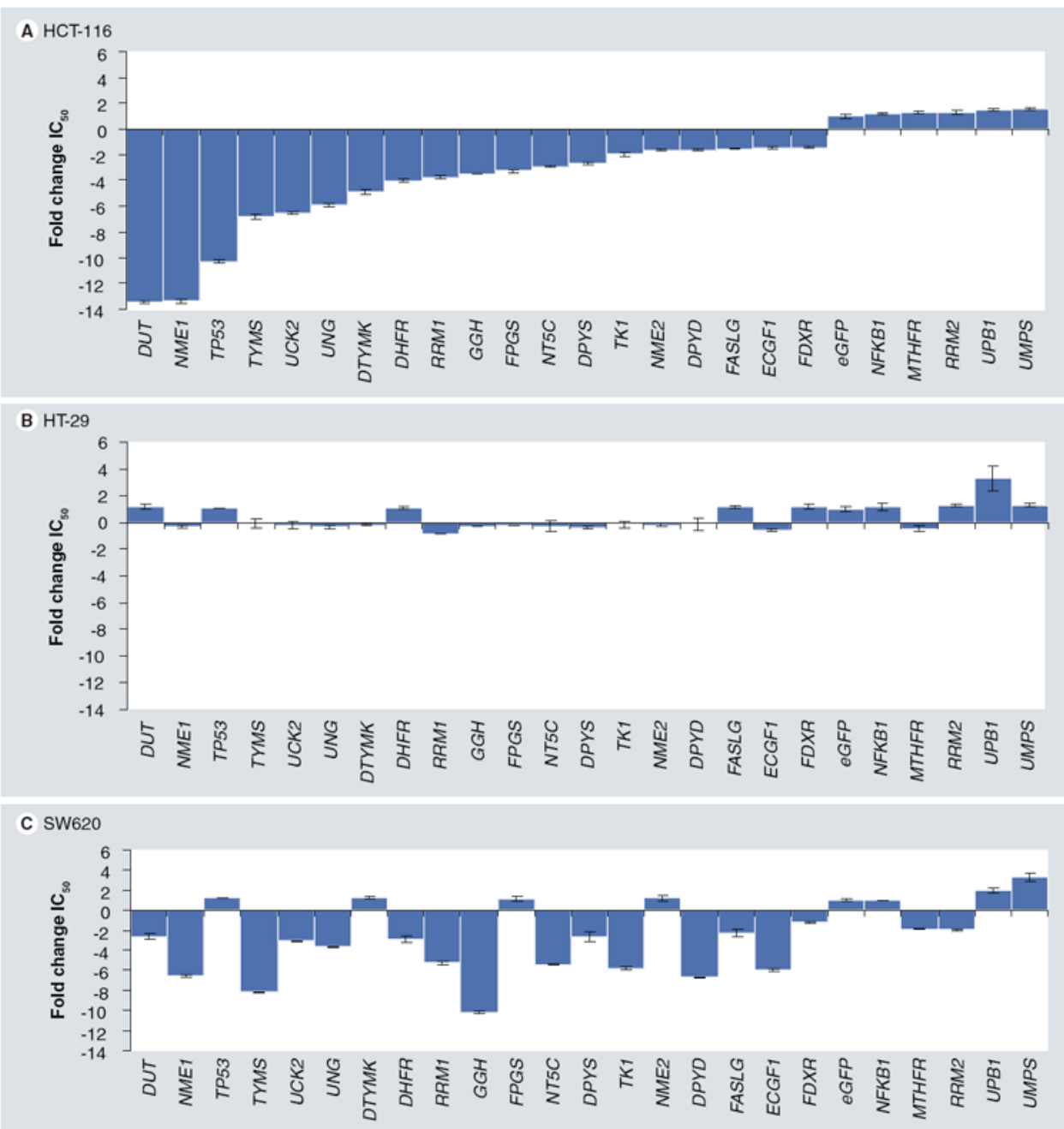

Figure 4. Profiles of cell sensitivity of PharmGKB genes ordered by HCT-116 response Waterfall diagrams show fold change in the $\mathrm{IC}_{50}$ relative to control of each gene. Positive values represent fold change in $\mathrm{IC}_{50} \geq 1$ or more, and negative values represent fold change in $\mathrm{IC}_{50}$ of less than 1. Cell lines utilized were (A) HCT-116; (B) HT-29; and (C) SW620. 

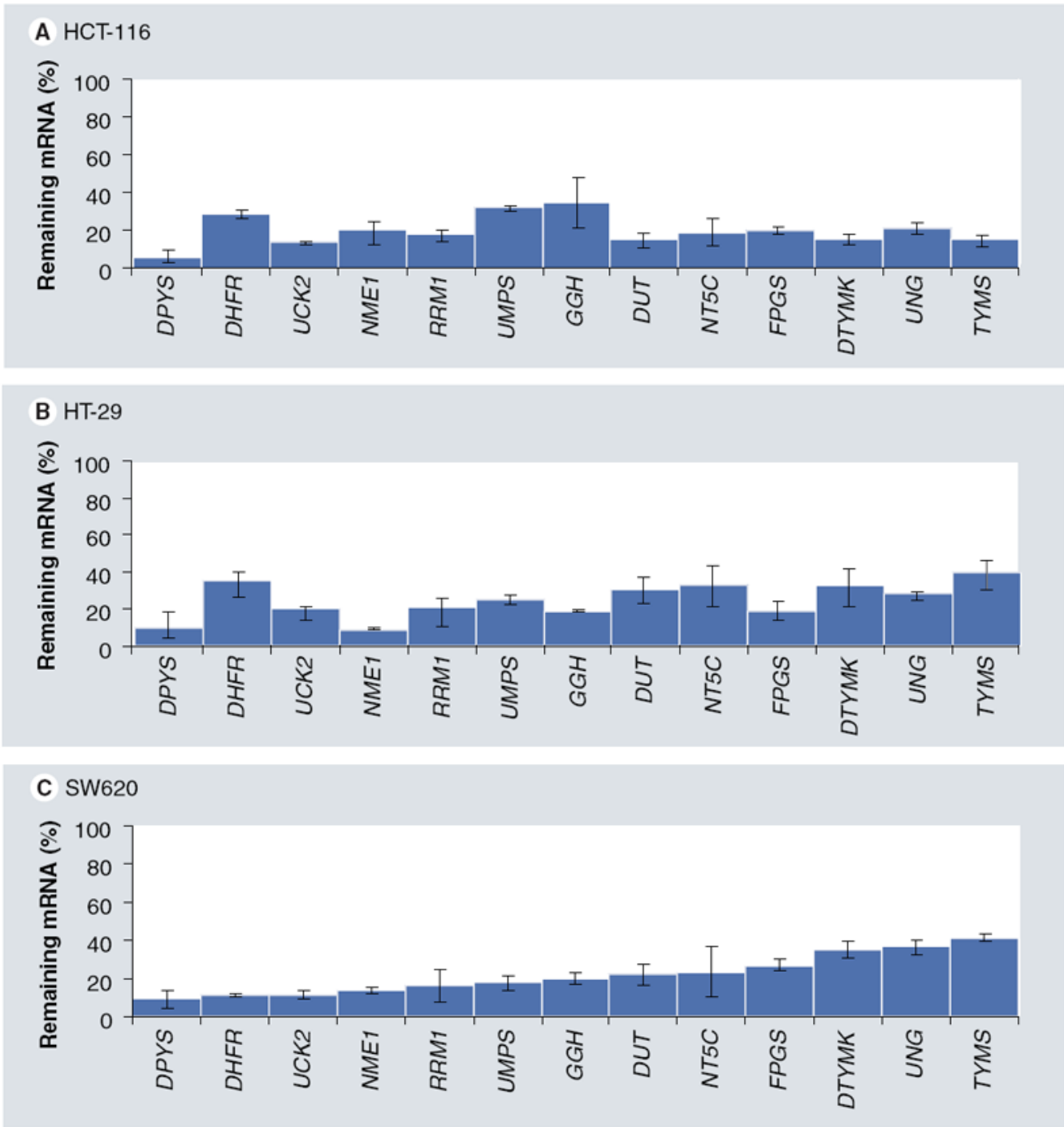

Figure 5. mRNA levels of target genes following shRNA knockdown

The histograms show the reduction in mRNA levels for the target genes $48 \mathrm{~h}$ following knockdown with shRNA plasmids in (A) HCT-116, (B) HT-29 and (C) SW620 colorectal cell lines. For each gene, data was expressed as mean \pm standard deviation for the selected 2-3 shRNAs. 

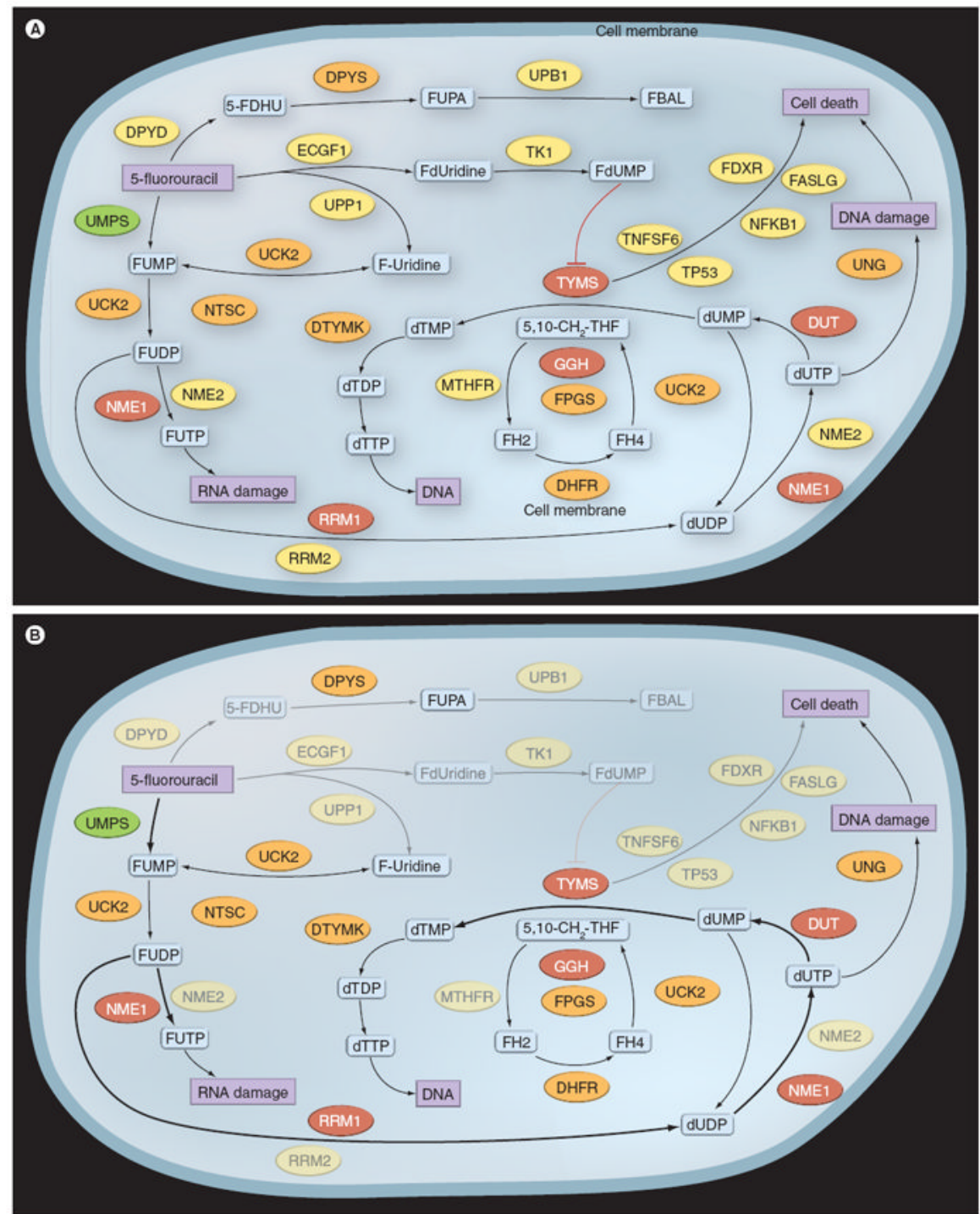

Figure 6. 5-fluorouracil functional drug pathway reflecting the relative impact of each gene (A) Phenotypes were: moderate sensitivity (orange, mean fold change of $\mathrm{IC}_{50}$ for active genes of 5 or less), strongly sensitive (red, mean fold change of $\mathrm{IC}_{50}$ for active genes $>5$ ), resistant (green, mean fold change of $\mathrm{IC}_{50}$ for active genes >2) and normal (yellow, no significant change in $\mathrm{IC}_{50}$ ). (B) Modified 5-fluorouracil drug pathway highlighting the gene modulators prioritized by RNAi strategy.

Adapted with permission from [102]. 